\title{
st \\ Desconhecimento e liberdade no caminho de uma nova ciência do comportamento
}

\author{
Robson Nascimento da Gruz
}

\begin{abstract}
茴
RESUMO

Interpretações históricas do percurso científico inicial de Skinner destacam as inovações teóricas, empíricas e instrumentais de seu esboço de uma ciência do comportamento. Apesar desse empenho historiográfico, um aspecto tem sido tratado de modo secundário na análise dessa fase da carreira de Skinner, a saber, os impactos dos contextos institucionais da universidade de Harvard nos rumos de sua trajetória e ciência. O objetivo deste artigo é investigar esse aspecto por meio da apreciação das práticas institucionalizadas dos Departamentos de Psicologia e de Fisiologia Geral daquela universidade, e suas relações com a emergência da proposta científica de Skinner e suas peculiaridades teóricas e metodológicas. De acordo com nossa interpretação, singularidades dos primórdios da ciência skinneriana são compreendidas de modo mais amplo quando identificadas as condições institucionais que permitiram a Skinner se distanciar do mainstream da psicologia experimental estadunidense. Por fim, sugerimos que embora este estudo refira-se à história de um eminente cientista, em um momento e cenário histórico específicos, ele serve para ilustrar o papel de controles sociais, inerentes à prática científica, nos rumos da carreira de cientistas e suas produções intelectuais.
\end{abstract}

PALAVRas-CHAVE • Skinner. Autobiografia científica. Análise do comportamento. História da psicologia. História do behaviorismo.

\section{INTRODUÇÃO}

Embora a historiografia da ciência enfatize cada vez mais as relações intrínsecas entre a vida dos cientistas e suas produções intelectuais, informações referentes à biografia de cientistas ainda ocupam lugar secundário no ensino de história da ciência. Não por acaso, em livros textos e manuais introdutórios, biografias científicas são descritas em barras laterais ou em tópicos separados. Os próprios historiadores da ciência conservaram, muitas vezes, a vida dos cientistas como um capítulo isolado da ciência (cf. Porter, 2006). Motivo para tanto seria a definição, ainda hegemônica, de ciência como empreendimento puramente racional. Essa concepção, amparada pela forte distinção entre fatos e valores, propagada ao longo dos últimos quatro séculos, estabeleceu a separação radical entre os fatos científicos e a vida dos cientistas como uma relação indesejável e incompatível com a moral científica moderna (cf. Shapin, 2008). 
A historiografia dos primórdios do behaviorismo do psicólogo estadunidense Burrhus Frederic Skinner (1904-1990) é exemplar do tratamento secundário dispensado à vida de um cientista. Essa historiografia enfatiza, especialmente, o rápido avanço do esboço de uma ciência do comportamento como resultado das inovações instrumentais, dos achados empíricos e das formulações teóricas do jovem Skinner, no início da década de 1930 (cf. Coleman, 1981, 1987; Iversen, 1992; Micheletto, 1995; Moxley, 1992; Sério, 1990). Apesar da riqueza e sofisticação dessa historiografia, o foco conceitual dessa produção evidencia como outros aspectos do início da carreira de Skinner receberam escassa atenção. Entre esses fatores estaria a surpreendente ausência de escritos sobre como Skinner conduziu suas relações sociais no âmbito acadêmico (cf. Cerullo, 1996). Tendo em vista essa lacuna historiográfica, o propósito deste artigo é analisar a vinculação entre o percurso inicial de Skinner, durante seu doutorado em Harvard (1928-1931), e a emergência do esboço de sua peculiar ciência do comportamento dentro da estrutura institucional daquela universidade.

É preciso dizer que, conquanto investigada de modo escasso, a carreira de Skinner sempre fez parte da historiografia do behaviorismo. Todavia, quando mencionada, quase sempre figura de modo pouco preciso, no máximo por meio de hipóteses não desenvolvidas e descrições genéricas acerca de seus prováveis efeitos na trajetória de Skinner e de sua obra. Dois acurados exames conceituais (cf. Coleman, 1981; Sério, 1990) ilustram a referência genérica aos papéis desempenhados pelos contextos acadêmicos e institucionais nos quais Skinner esteve inserido no começo de sua carreira em Harvard.

Na primeira análise, Coleman avalia as características das pesquisas iniciais de Skinner como provável resultado da sua não adesão à psicologia experimental praticada em Harvard. Embora entenda que a razão parcial para tanto foi a vinculação de Skinner ao Departamento de Fisiologia Geral e ao seu chefe, William J. Crozier, a interpretação de Coleman enfatiza a singular acomodação do conceito de reflexo nos primórdios do projeto científico skinneriano. Não foi seu objetivo elucidar como a prática institucionalizada da psicologia e da fisiologia em Harvard e as relações estabelecidas por Skinner naqueles ambientes incidiram nos usos particulares que ele fez do conceito de reflexo. Desse modo, mesmo que sugira a relevância do cenário institucional e das vinculações de Skinner, para Coleman uma história focada nesse aspecto seria "uma história que não podemos explorar aqui" (1981, p. 211).

Em consonância com a explicação de Coleman sobre o início da carreira de Skinner na psicologia, Sério (1990) conjectura que a vinculação a Crozier isentou Skinner de recorrer à produção científica da psicologia experimental, isolando-o de críticas advindas desse campo e da necessidade de utilizar seus métodos canônicos. Ademais, a autora alega que, "mais do que uma mera influência inicial, estes dois fato- 
res - o isolamento da psicologia e a vinculação a Crozier - parecem de alguma forma ter possibilitado um certo estilo de trabalho que se manteria, pelo menos, até 1938" (Sério, 1990, p. 52). Conquanto levante tal hipótese, como Coleman, Sério mantém sua análise orientada para o nível conceitual da ciência skinneriana em seus primórdios.

Na produção acerca da trajetória biográfica do psicólogo há um número expressivo de informações alusivas às relações sociais desse cientista no âmbito institucional de Harvard. Contudo, essas informações são descritas sem maiores considerações dos prováveis impactos do ambiente institucional nos rumos do projeto científico de Skinner. Assim, embora forneça indícios para tanto, as práticas institucionalizadas da ciência em Harvard, igualmente, aparecem como pano de fundo, e não como parte integrante das condições que propiciaram sua formulação inicial de ciência (cf. Bjork, 2006; Evans, 1968; Wiener, 1996; Weigel, 1977)

A biografia mais detalhada de Skinner revela essa tendência. Ao discutir a passagem inicial dele por Harvard, Bjork (cf. 2006, p. 96) alega, por exemplo, que Skinner teria sido "moldado", durante o doutorado, em determinadas tradições de pesquisas psicológicas; e que sua tese de doutorado seria prova do seu rompimento com aquelas tradições. Essa visão desconsidera, entre outras coisas, que Skinner não foi "moldado" por qualquer tradição de pesquisa psicológica em Harvard, uma vez que rejeitou de antemão a psicologia praticada naquela instituição. Por sua vez, não rompeu com as tradições ali presentes, porque nunca aderiu a elas. Portanto, é notado que Bjork não se aprofundou o suficiente, por exemplo, nos relatos autobiográficos de Skinner, que expõem o desprezo e a falta de adesão desse cientista à psicologia praticada em Harvard. Com isso, deixa de analisar os limites do controle institucional naquele espaço acadêmico, que forneceram a Skinner condições para não se vincular às tradições de pesquisa psicológica ali existentes.

Para realizar uma análise na qual as relações sociais de Skinner, dentro da estrutura institucional da Universidade de Harvard, se incluam na interpretação dos determinantes da emergência de seu esboço de uma ciência do comportamento, recorremos, principalmente, aos três volumes de sua autobiografia (cf. Skinner, 1979; 1984a; 1984,b). Tais fontes provêm informações, referentes às vinculações entre a carreira de Skinner e sua produção científica, inexistentes em grande parte das análises acerca da sua trajetória em Harvard. Entretanto, é preciso notar que o relato autobiográfico de Skinner não apresenta tais informações de modo sistematizado. A autobiografia de Skinner tem sido caracterizada pela dispersão temática e aparente ausência de unidade lógica (cf. Coleman, 1987; Krasner, 1980). Isso significa, entre outras coisas, a ausência de capítulos específicos acerca de suas relações sociais no âmbito acadêmico de Harvard, ou de qualquer outro tema. Contudo, isso não quer dizer ausência de coerência interna na narrativa autobiográfica de Skinner. Sobre isso, vários estudos históri- 
cos (cf. Cerullo, 1996; Coleman, 1985a; Demorest \& Siegel, 1996; Krasner, 198o; Siegel, 1996) mostram que uma leitura sistematizada daquele texto permite a identificação de padrões que apresentam vinculações entre si. Procedimento que possibilitou, no caso deste estudo, a localização de três dados históricos que perpassam a trajetória inicial do psicólogo durante seu doutorado, a saber: seu suposto desconhecimento acerca da produção científica da psicologia experimental; o isolamento da psicologia praticada em Harvard; e a liberdade científica e o apoio a projetos individuais experimentados no Departamento de Fisiologia daquela instituição. ${ }^{1}$

Com o auxílio de outras fontes, essas questões serão doravante discutidas por meio de cinco pontos:

(1) o ingresso de Skinner em um campo de conhecimento desconhecido;

(2) as condições científicas e institucionais desfavoráveis do Departamento de Psicologia em Harvard;

(3) as condições científicas e institucionais favoráveis do Departamento de Fisiologia Geral;

(4) o incentivo, liberdade e "desconhecimento" como parte da explicação para a emergência de uma nova ciência do comportamento;

(5) a transgressão do conceito de reflexo e a formulação de um novo método de pesquisa como resultado parcial da prática institucionalizada do Departamento de Fisiologia Geral e do isolamento do Departamento de Psicologia.

A partir da análise desses aspectos, argumentamos que o rápido avanço do esboço do projeto científico de Skinner e suas peculiaridades teóricas e metodológicas, que se mostraram incompatíveis, em pontos cruciais, com o mainstream da psicologia experimental estadunidense de meados da década de 1930, têm sua compreensão expandida quando expostas as relações sociais daquele cientista dentro do ambiente institucional de Harvard.

Por fim, embora esta análise seja versão parcial e reduzida de tese mais ampla acerca do percurso acadêmico e profissional de Skinner, entre as décadas de 1930 e 1960, e suas relações com a organização comunitária da sua ciência, compreende-se que um estudo das relações sociais na ciência - derivado, principalmente, de fontes biográficas e autobiográficas - possibilita a expansão da consciência histórica sobre aspectos envoltos na trajetória de cientistas e suas produções intelectuais (cf. Cruz, 2013).

1 Ainda sobre a autobiografia de Skinner, alguém poderia alegar que um estudo biográfico de Skinner não seria necessário, uma vez que os três volumes de sua autobiografia já teria nos dito tudo que havia para dizer sobre a sua vida. Julgamento equivocado, na visão de Woodward (1996), pois o estilo singular da autobiografia de Skinner permite novas interpretações sobre sua vida e obra. 


\section{O INGRESSO EM UM TERRENO DESGONHEGIDO}

Skinner iniciou sua formação acadêmica no Hamilton College, onde graduou-se em língua inglesa e literatura no ano de 1926. O período entre o final de sua graduação e a decisão pelo ingresso no doutorado em psicologia de Harvard, no decorrer de 1927, foi descrito por ele como seu pior ano (dark year) (cf. Elms, 1981; Skinner, 1984a). Fase essa em que, após a tentativa frustrada de tornar-se escritor e sua decorrente insurreição contra a literatura, Skinner elegeu a psicologia como a área do conhecimento na qual daria continuidade a sua formação acadêmica.

Apesar de influenciado por nomes como Pavlov e Watson (cf. Skinner, 1984a, 1984,b, 1970), a opção de Skinner pelo doutorado em psicologia e sua precoce simpatia pelo behaviorismo ocorreram quando seu conhecimento acerca dessa abordagem era incipiente. Mesmo com manifesta afeição pela psicologia, a escolha de um doutorado na área não resultou da imediata conversão de Skinner à ciência psicológica. Referindo-se também à fuga de um futuro incerto na literatura, ele recordou: "eu tinha vindo para Harvard não porque eu estava totalmente comprometido a me converter à psicologia, mas porque eu estava escapando de uma alternativa intolerável" (Skinner, 1979, p. 37 ).

Ainda que as experiências pessoais e as influências teóricas do jovem Skinner sejam de amplo valor heurístico para o exame das razões de sua decisão de cursar o doutorado em psicologia, esses aspectos não serão investigados (cf. Bjork, 2006; Elms, 1981; Moore, 2005a, 2005b, 2005c; Skinner, 1979, 1984a). Para os propósitos do presente artigo, a respeito do período que antecede a decisão de Skinner, ocorrida entre o final de 1926 e outubro de 1927 , destaca-se o seu baixo grau de conhecimento sobre a psicologia. Durante a graduação, por exemplo, afirmou ter ouvido apenas uma vez alusão à psicologia e, ainda assim, isso se deu de modo breve e vago em uma disciplina de filosofia. Nas palavras dele: "a única instrução formal que eu recebi [em psicologia] durou dez minutos" (Skinner, 1970, p. 8). Em outra ocasião disse que: "a ciência que se preocupava com o comportamento (animal e humano) era chamada de psicologia, sobre a qual eu sabia muito pouco" (Skinner, 1984a, p. 292). Portanto, apenas quando principiou seu doutorado em Harvard, em setembro de 1928, Skinner estabeleceu contato direto com pesquisas e com pesquisadores do campo psicológico. ${ }^{2}$

2 Não obstante afirme saber muito pouco de psicologia antes de sua entrada no doutorado, Skinner (1984a) destacou que isso não significava que o objeto de estudo dessa ciência lhe fosse desconhecido, mesmo que de forma não científica. Tal alegação se baseou em suas experiências de infância como morador de uma fazenda e nas inúmeras oportunidades de observação do comportamento animal na natureza, bem como do comportamento de animais em cativeiro. Skinner também atestou que, desde a infância, sempre chamaram sua atenção análises e observações, ainda que imperfeitas, sobre o comportamento humano realizadas por outras pessoas. 
Tais relatos do escasso conhecimento de Skinner sobre a psicologia antes de seu ingresso no doutorado em Harvard são importantes à medida que designam a emergência de um relato disperso, mas recorrente em toda a sua autobiografia, a saber, a afirmação de que sabia muito pouco sobre a psicologia. Relato que, contudo, se tornou ambivalente ao longo do tempo e adquiriu função retórica bastante específica, como será discutido de modo detalhado posteriormente.

\section{DegadênGia INSTITUGIONAL E DEGEPÇÃo Gientífica: o gontato de Skinner gom a PSigologia em Harvard}

Um dos problemas históricos da psicologia para Skinner (1979), quando ingressou em Harvard, era sua configuração tardia como ciência natural e, portanto, na sua visão, o fato de ser uma das últimas ciências a se tornar independente da filosofia. Essa suposta deficiência da psicologia foi experimentada por Skinner em Harvard não somente em termos científicos, mas em termos institucionais, pois, no final da década de 1920, o Departamento de Psicologia daquela universidade se mantinha subordinado ao Departamento de Filosofia. Como mostra Capshew (1999), mesmo sendo uma das principais universidades estadunidenses da primeira metade do século xx, Harvard foi a última a ter seu Departamento de Psicologia desvinculado do Departamento de Filosofia. Por essa e por outras razões - também discutidas neste artigo -, nos primeiros meses de doutorado, Skinner (1979) lamentou estar matriculado ao mesmo tempo em dois departamentos para ele inconciliáveis. ${ }^{3}$

Além do problema de dependência à filosofia, no final da década de 1920, a psicologia em Harvard enfrentava uma de suas piores crises institucionais desde sua fundação. O declínio da área iniciou com a morte de William James, em 1910, e com a saída da instituição de eminentes nomes da psicologia experimental, como Edward C. Tolman, Robert M. Yerkes e Edwin B. Holt. Todos eles se retiraram de Harvard durante a década de 1910 em razão da crescente decadência da psicologia experimental na ins-

30 descontentamento de Skinner pela vinculação do Departamento de Psicologia ao Departamento de Filosofia não pode ser compreendido como falta de apreço pelo debate filosófico. Grande parte das preocupações iniciais de Skinner, no doutorado, foram orientadas por questões de cunho epistemológico, que definiram posteriormente muitos dos rumos de sua ciência do comportamento (cf. Chiesa, 1994; Moxley, 1992; Micheletto, 1995, 2000; Moore, $2005 \mathrm{a}, 2005 \mathrm{~b}, 2005 \mathrm{c}$ ). Vale dizer, portanto, que embora não seja nosso foco de análise, a autobiografia de Skinner é fonte valiosa para investigar também como determinadas influências filosóficas desse cientista podem ter sido mediadas por contatos informais, no ambiente de Harvard, durante seu doutorado e pós-doutorado. O contato de Skinner com o filósofo da ciência Willard V. O. Quine, por exemplo, é emblemático da importância das suas relações sociais naquele contexto, uma vez que foram colegas de pós-doutorado e compartilharam interesses teóricos sobre o tratamento da linguagem que sugerem influência mútua em seus trabalhos (cf. Quine, 1985; Skinner, 1984;a, 1984,b). 
tituição e da oferta de melhores oportunidades de trabalho em outras universidades (cf. O’Donnell, 1985; Triplet, 1992).4

Agravante do contínuo declínio da psicologia em Harvard foi a recusa do então chefe de departamento, o psicólogo experimental Edwin G. Boring, de aderir à tendência em ascensão da pesquisa aplicada da psicologia estadunidense. Como principal discípulo do proeminente líder do estruturalismo inglês, Edward B. Titchener, Boring defendeu de forma radical o ideal acadêmico de pesquisa pura e atacou a intensa convergência, no início dos anos 1920, ao ideal social de serviço e eficiência gerado pelas demandas do pós-guerra (cf. O’Donnell, 1979, 1985). Para Boring, eram indubitáveis os danos profundos da ascendência da pesquisa aplicada na composição de uma psicologia pura, fundamentada em concisa base experimental (cf. O’Donnell, 1979). Desse modo, ao assumir a chefia do Departamento de Psicologia, em 1924, Boring fez do cargo "uma oportunidade de empreender a missão incompleta de seu mentor para resgatar a psicologia em Harvard dos filósofos e da psicometria" (Triplet, 1992, p. 225).

A defesa de Boring de uma psicologia experimental avessa à aplicação gerou críticas e resistências à adoção em Harvard de qualquer perspectiva psicológica aplicada - caso do behaviorismo, desvalorizado por esse cientista que se tornou uma das principais figuras institucionais da psicologia estadunidense da primeira metade do século xx (Capshew, 1999). Assim, Skinner principiou sua vida acadêmica na psicologia em um ambiente científico precário e inóspito à abordagem com a qual se identificara pouco antes de sua admissão em Harvard.

Dado o panorama de Harvard no final da década de 1920, são também representativas das condições experimentadas por Skinner nessa fase suas impressões acerca da ciência psicológica praticada naquela universidade. Quase sempre, essas impressões, provenientes da participação em disciplinas e seminários de psicologia, foram descritas em tom de desapontamento e frustração. O motivo para tanto era a ausência de conteúdos semelhantes àqueles encontrados na fisiologia de Pavlov e no behaviorismo de Watson, autores responsáveis por fornecer a Skinner uma definição propedêutica da psicologia como ciência do comportamento, a partir da noção de reflexo condicionado. Por essas razões, Skinner lamentou: "a psicologia, como eu a encontrei em Harvard, não tinha sido tudo que eu esperava, e eu sempre gostei de biologia” (Skinner, 1979, p. 26).

4. Não apenas Harvard, mas diversas universidades estadunidenses experimentaram dificuldades, nas primeiras décadas do século xx, em função das escassas políticas científicas e diminuição do financiamento das pesquisas. Todavia, ocorreram mudanças nesse cenário a partir do final da década de 1920, quando os psicólogos estadunidenses estabeleceram relações próximas com a arena política e começaram a fazer parte de comissões responsáveis pela organização política da ciência nos Estados Unidos, que naquele momento priorizou massivamente o investimento em pesquisas aplicadas (cf. Capshew, 1999; Samelson, 1985). 
Quase todas as disciplinas de psicologia cursadas por Skinner no doutorado entre 1928 e 1929 (entre elas, psicologia do indivíduo, psicologia clínica, psicologia experimental e laboratório quantitativo), foram percebidas como distantes daquilo que ele realmente queria estudar: o comportamento como um todo (cf. Skinner, 1979, p. 8, 27). Um exemplo dessa insatisfação é observado quando, ao frequentar um seminário de Leonard Troland, psicólogo especialista em estudos sobre a visão, comentou que "no primeiro encontro, eu achei a palestra incrivelmente estúpida e desisti do curso" (Skinner, 1979, p. 8).5

O único contato formal de Skinner com o behaviorismo em seus primeiros meses em Harvard ocorreu em um seminário lecionado pelo professor visitante Walter S. Hunter, da Universidade de Clark. A participação na disciplina de Hunter induziu Skinner a declarar que seu primeiro ano de doutorado no Departamento de Psicologia não decorreu "sem as suas brilhantes marcas behavioristas" (Skinner, 1979, p. 11). Entretanto, o contato com Hunter foi insuficiente para amenizar as recorrentes queixas de Skinner em relação à psicologia ensinada naquele departamento. Além do mais, Hunter não exerceu influência identificável nos seus interesses conceituais e metodológicos. Na verdade, Skinner discordou teoricamente de Hunter e afirmou, em mais de uma ocasião, que ele não compreendida suas pesquisas (cf. Skinner, 1979, p. 31, 156, 170).

A despeito de ser factível a identificação precoce de Skinner com o behaviorismo, os seus comentários sobre a vinculação com essa abordagem, entre o final de sua graduação e o início do doutorado, mostram a impossibilidade de designá-lo como estrito adepto do behaviorismo naquele momento. Para o próprio Skinner, isso é evidenciado na manutenção de sua linguagem mentalista, pouco antes e logo após seu ingresso em Harvard, e, principalmente, em seu desconhecimento teórico quase completo acerca daquela perspectiva psicológica. Tais fatores, contudo, não o impediram de manifestar, no primeiro mês de aulas, críticas públicas ao mentalismo e defesas do behaviorismo, mesmo sendo um mero calouro de doutorado sem formação em psicologia. Segundo ele, nas primeiras disciplinas de psicologia cursadas em Harvard, "eu mal poderia saber sobre o que estava falando. Eu não tinha feito nenhum curso de psicologia antes da faculdade e estava na graduação há apenas um mês" (Skinner, 1979, p. 14). Todavia, seu conhecimento elementar não foi obstáculo para sua prematura defesa do behaviorismo, como afirmado em entrevista concedida seis décadas após seu

5 Em 1926, dois anos antes do ingresso de Skinner em Harvard, Fred S. Keller (o principal interlocutor de Skinner na década de 1930) fez uma declaração representativa da compatibilidade de pensamento estabelecido nos anos seguintes entre os dois cientistas. Na ocasião também calouro do doutorado em psicologia e um dos únicos alunos com assumida adesão ao behaviorismo, Keller descreveu seu descontentamento com a tendência mentalista predominante em Harvard; e de modo semelhante à opinião de Skinner, em relação ao curso do professor Troland, afirmou que frequentá-lo "foi uma decepção. Talvez como a maior autoridade mundial em visão humana, ele fosse mais subjetivista do que o próprio Titchener" (Keller, 2009, p. 104). 
ingresso em Harvard: "eu me tornei um grande defensor do behaviorismo antes de saber qualquer coisa sobre ele" (Skinner apud Wiener, 1996, p. 47).

Embora mencione nomes como Watson e Pavlov como responsáveis por sua aproximação do behaviorismo, durante a sua permanência em Harvard, inexistem vestígios de qualquer compromisso declarado de Skinner com algum autor ou perspectiva específica do campo. Explicação para isso talvez seja, como sugere Samelson (1981), a própria configuração do cenário behaviorista da primeira metade do século xx, que diferente do que sustentaram versões historiográficas simplistas da psicologia estadunidense - nunca se estabeleceu como escola psicológica monolítica provedora de acordos teóricos e metodológicos compartilhados consensualmente entre seus adeptos. Na realidade, o mais provável é que tal abordagem tenha sido "em grande medida um posicionamento metafísico atraente para diversas preocupações ideológicas" (Samelson, 1981, p. 35).

No caso de Skinner - e, provavelmente, de outros jovens estudantes de psicologia simpáticos ao behaviorismo -, supõe-se que sua adesão à tendência estivesse menos vinculada a qualquer posição definida, correspondendo, sim, à estima declarada a compromissos metafísicos tão comuns nas distintas perspectivas behavioristas, como o determinismo e o antimentalismo; e o apreço a compromissos ideológicos como a ordem e o planejamento científico da sociedade (para uma análise das prováveis compatibilidades entre as aspirações ideológicas e filosóficas do jovem Skinner e o behaviorismo no começo do século xx, cf. Moore, 2005a, 2005b, 2005c). Foi nesse sentido que, sobre seu primeiro ano de doutorado, Skinner declarou: "eu não era um behaviorista, eu não sabia nada sobre o behaviorismo, mas eu era um behaviorista dedicado em meu posicionamento" (Skinner apud Wiener, 1996, p. 32). Por outro lado, é plausível conjecturar que a ausência de adesão confessa a qualquer autor ou vertente behaviorista específica seja indício da prematura aspiração de Skinner de fundar sua própria versão do behaviorismo.

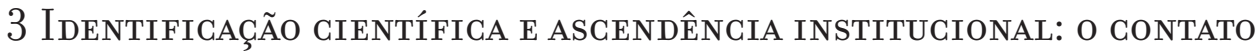 de Skinner com Crozier e gom o Departamento de Fisiologia Geral}

O Departamento de Fisiologia de Harvard foi instituído por meio de uma subdivisão do Departamento de Biologia, sendo coordenado, desde 1925, por William J. Crozier. Discípulo do fisiologista Jacques Loeb, Crozier trabalhou com pesquisas tradicionais em biologia até se tornar partidário da recém-criada fisiologia geral (cf. Hoagland \& Mitchell, 1956). Após assumir a coordenação do Departamento de Fisiologia, Grozier passou a desenvolver também investigações com medidas de reação em organismos 
intactos, situando seu laboratório na fronteira entre a biologia e a psicologia. $\mathrm{O}$ resultado disso foi a transformação do Departamento de Fisiologia em uma "Meca" para estudiosos desses dois campos do conhecimento (cf. Bjork, 2006).

Uma das primeiras impressões de Skinner ao frequentar o Departamento de Fisiologia foi que "Crozier era ambicioso" (Skinner, 1979, p. 17), pois, de maneira contumaz, buscava meios de expandir sua influência institucional e científica em Harvard. A ampliação do espaço físico e a melhoria do laboratório de fisiologia comprovam o esforço de Crozier para criar um ambiente acadêmico fecundo. Skinner também salientou que Crozier "estava construindo um império de outras maneiras" (1979, p. 17), pois suas estratégias organizacionais e sua política científica eram incomuns. Por exemplo, em vez de contratar cientistas experientes e com reputação estabelecida em seus campos de pesquisa - como era esperado de qualquer recém-empossado chefe de departamento -, Crozier admitiu e treinou uma equipe de jovens e promissores pesquisadores, tanto da biologia quanto de áreas afins (cf. Bjork, 2006; Hoagland \& Mitchell, 1956; Skinner, 1979).

Embora Skinner eleja em primeiro lugar o valor da ciência praticada no Departamento de Fisiologia como causa de sua aproximação daquele ambiente, ele igualmente nomeou as condições institucionais e o perfil científico e institucional de Crozier como determinantes de seu apreço por aquele departamento. Com respeito aos fatores científicos, as impressões de Skinner sobre as disciplinas cursadas no Departamento de Fisiologia denotam sua imediata apreciação do conteúdo ensinado naquele ambiente. Em relação à primeira disciplina que frequentou, "Fisiologia geral 5 ", em tom de entusiasmo, Skinner asseverou: "esse foi exatamente o curso que eu procurava" (1979, p. 17). O motivo para tanto foi que, na disciplina lecionada pelo principal apoiador de Crozier, o professor Hudson Hoagland, Skinner se sentiu aliviado, assim como admirado por, finalmente, alguém em Harvard discutir o conceito de reflexo condicionado. Skinner declarou ter compreendido na disciplina de Hoagland que, embora os reflexos condicionados e incondicionados pavlovianos fossem produzidos por secreções glandulares, havia espaço nesses conceitos para uma explicação do comportamento físico de um organismo intacto: "algo muito próximo do que eu estava ordinariamente chamando de comportamento" (1979, p. 17). No mesmo curso, Skinner conheceu as pesquisas de Rudolph Magnus sobre o reflexo, que envolviam postura e locomoção, e entrou em contato com o trabalho de outro fisiologista de Harvard, John Fulton - que havia acabado de publicar seu livro Muscular contraction and the reflex control of movement, de 1926, bem como lhe foi apresentado o livro de Sherrington, Integrative action of the nervous system, de 1906, do qual mencionou a leitura com entusiasmo.

O primeiro efeito de sua estima pelo conteúdo das disciplinas cursadas no Departamento de Fisiologia geral foi o surgimento da dúvida sobre em que departamento 
realizaria sua pesquisa de doutorado, uma vez que a transferência para o Departamento de Fisiologia era a opção mais coerente com suas predileções científicas. Contudo, mesmo sendo nítida a compatibilidade entre seus interesses e a ciência praticada na fisiologia em Harvard, Skinner adiou sua decisão por um semestre, a fim de ter uma percepção mais transparente sobre os setores de fisiologia e psicologia (cf. Bjork, 2006; Skinner, 1979).

O período propiciou não somente realce das discrepâncias entre as ciências praticadas nos dois departamentos, mas assegurou maior conhecimento acerca da estrutura institucional de cada um deles e do nível de incentivo e, principalmente, de liberdade para empreender projetos individuais nesses ambientes. Em correspondência enviada aos seus pais no final do primeiro semestre de 1929, Skinner (1979) expôs as razões que o levaram a migrar para o Departamento de Fisiologia. Antes de tudo, mencionou que Crozier e Hoagland persuadiam aqueles que julgavam serem os mais promissores alunos do doutorado em psicologia a se transferirem para o Departamento de Fisiologia - e que ele era um dos alunos abordados diretamente por tais professores. Na mesma carta, Skinner relata como a fisiologia estava próxima daquilo que ele buscava estudar na psicologia: o comportamento como um todo. Com igual ênfase, porém, foram citadas causas de ordem econômica, estrutural e influência social como contribuintes para sua escolha do Departamento de Fisiologia. Nas palavras de Skinner,

a fisiologia do sistema nervoso é praticamente psicologia e as instalações do Departamento de Fisiologia são melhores. Eles acabaram de receber uma verba de 6 milhões de dólares e estão prestes a construir um novo edifício que irá custar 2 milhões no próximo ano. Crozier já é amplamente conhecido e neste momento o Departamento de Fisiologia é muito mais importante aqui do que o Departamento de Psicologia. Hoagland está particularmente ansioso por me ter no departamento. Isto significa, não só que um doutorado em fisiologia seria a melhor coisa, mas que haveria uma boa oportunidade de alinhar-se com um laboratório local ao abrigo deste novo investimento e obter uma boa posição, com nada a fazer além de minha própria pesquisa. Pode ser possível trabalhar no Departamento de Fisiologia e ainda obter meu doutorado em psicologia, como eu planejei. Eu vou falar sobre isso com os chefes de ambos os departamentos. Crozier tem sido muito bom para mim e parece ansioso em me ajudar. Ele é um big gun no campo e essa seria uma boa oportunidade para alinhar-se com um homem influente (Skinner, 1979, p. 25-6).

A descrição de fatores econômicos, estruturais e de influência social do Departamento de Fisiologia expõe um ambiente institucional oposto àquele do Departamento 
de Psicologia de Harvard, no final da década de 1920 - departamento esse, como antes mencionado, no auge de sua precariedade institucional e incompatível cientificamente com as predileções behavioristas do jovem Skinner. Assim, apesar de citar certa indecisão inicial, a definição do departamento em que efetuaria sua pesquisa de doutorado ocorreu sem grandes conflitos. Se algum desacordo existiu e se Skinner não se decidiu de imediato pelo Departamento de Fisiologia Geral, é provável que isso tenha ocorrido em razão das implicações institucionais envolvidas nesse processo; como uma possível represália de Boring ou algo similar. Possibilidade presumida pela observação das críticas públicas de Boring ao behaviorismo e à adesão de Skinner a essa abordagem (Skinner, 1979, p. 80, 93-4). ${ }^{6}$ O fato é que a transferência para o Departamento de Fisiologia se encaminhou da forma almejada. Skinner obteve permissão para realizar sua pesquisa de doutorado no Departamento de Fisiologia Geral e, também, se manteve vinculado ao Departamento de Psicologia, recebendo autorização para obter seu título de doutorado nessa área.

Entende-se, portanto, que a opção pelo Departamento de Fisiologia foi produto de diversas ordens: científica e epistemológica, uma vez que Skinner assumiu sua posição behaviorista (mesmo que de maneira um tanto imprecisa) e expôs como a noção de comportamento nas disciplinas e pesquisas do Departamento de Fisiologia estava próxima daquilo que ele buscava estudar; econômica, dadas as melhores condições materiais do Departamento de Fisiologia e a situação de precariedade do Departamento de Psicologia em Harvard; por último, influência social, pois Skinner salientou o reconhecimento do Departamento de Fisiologia Geral e as vantagens de estar associado a um pesquisador influente como Crozier.

\section{InGENTIVO, LibERDADE E "DESGONHEGIMENTo" NO CAMINHO DE UMA NOVA GIÊNGIA DO GOMPORTAMENTO}

Estar associado ao laboratório de Crozier significava, antes de tudo, desfrutar de toda a liberdade científica e institucional oferecida por esse pesquisador. Skinner enfatizou tal aspecto ao se referir a seu ingresso no Departamento de Fisiologia Geral e ao expe-

\footnotetext{
6 Apesar de Boring ser mencionado por Skinner como um disciplinador, contrário aos seus planos de fundar uma ciência do comportamento e um veemente crítico do behaviorismo, Boring proveu-lhe apoio institucional em mais de uma ocasião e sempre reconheceu as capacidades científicas de Skinner. Exemplo desse reconhecimento desvinculado da aceitação de sua posição científica é a carta de recomendação escrita por Boring para a comissão avaliadora do National Research Council Fellowship. Nessa correspondência, Boring classificou Skinner como um provável gênio e considerou que seu único defeito era o desejo de fundar uma ciência do comportamento. Intenção que, na sua visão, seria abandonada caso Skinner fosse contemplado com aquela bolsa de pesquisa (cf. Bjork, 2006, p. 101).
} 
rimentar as condições propiciadas por Crozier. Sobre isso ele afirmou em tom de satisfação: "ele me apoiou, me deu espaço, me deu dinheiro, me promoveu a bolsista e assim por diante, mas ele nunca disse: 'olha, por que você não faz algo com coeficiente de temperatura ou algo desta maneira?"' (Skinner apud Bjork, 2006, p. 85).

A existência de um ambiente agradável e o incentivo à realização de pesquisas individuais eram dois atributos reconhecidos no Departamento de Fisiologia Geral e no laboratório de Crozier (cf. Bjork, 2006; Skinner, 1979). Para a ocupação desses espaços, Crozier buscava alunos confiantes, habilidosos e decididos a seguir seus próprios interesses. Provido de todas essas qualidades, Skinner foi avaliado por Crozier como um de seus alunos mais promissores (cf. Bjork, 2006). Em termos práticos, o incentivo do Departamento de Fisiologia à busca por interesses individuais significou plena liberdade para que Skinner se dedicasse a suas pesquisas sem sujeitar-se à imposição de teorias, temas e métodos de investigação. Condição assumidamente valorizada por Skinner quando expressa que "Crozier nunca tentou me aproximar do seu campo, nem nunca levou crédito por alguma coisa que fiz" (Skinner, 1979, p. 100).

A ausência de imposição científica, o desprendimento com créditos científicos e a disponibilidade de tempo, espaço e estrutura para desenvolver apenas pesquisas de seu interesse foram consequências práticas responsáveis por induzi-lo a ter ótimo ritmo de trabalho. Sobre isso, observou: “minha presente condição é excelente. Eu estou trabalhando duro como jamais trabalhei, mas com tempo disponível e com objeto de estudo de minha própria escolha" (Skinner, 1979, p. 38). Aliás, o controle sobre as pesquisas de Skinner era tão ínfimo - se é que existiu alguma forma de monitoramento no sentido coercitivo da expressão - que todas as investigações realizadas por ele no decorrer de seu doutorado eram grandemente desconhecidas dos professores de ambos os departamentos aos quais estava vinculado (de fisiologia e de psicologia). A liberdade experimentada no laboratório de Crozier mostrou-se tão significativa que, durante suas práticas de pesquisa no doutorado, ele recordou com contentamento:

Eu trabalhei completamente sem supervisão. Ninguém sabia o que eu estava fazendo até que eu entregasse algum tipo de relatório contestável. Provavelmente os psicólogos pensaram que eu estava sendo orientado por Crozier e Hoagland, e esses devem ter pensado que alguém na psicologia estava de olho em mim, mas o fato era que eu estava fazendo exatamente o que me satisfazia (Skinner, 1979, p. 35$)$.

Em razão desse tipo de descrição recorrente acerca da liberdade experimentada no laboratório de fisiologia, Bjork (2006) sustenta que "com Crozier, Skinner poderia ser original e ter um caminho científico livre, sem medo de represálias ou ciúme pro- 
fissional" (p. 85). ${ }^{7}$ Por certo, Skinner teve sua autonomia garantida no Departamento de Fisiologia, mas seria ingenuidade presumir que disso resultou total independência com relação a teorias e métodos de investigação existentes nas pesquisas daquele departamento; tampouco que a proposta de uma nova ciência do comportamento - em gestação quando da permanência de Skinner em tal contexto - tenha sido resultado de qualquer ruptura com tradições de pesquisas fisiológicas e psicológicas. Ainda assim, como será discutido, a liberdade e autonomia no Departamento de Fisiologia refletiu em afastamento-isolamento significativo de Skinner tanto da fisiologia quanto da psicologia praticadas em Harvard e, em alguma medida, em distanciamento do mainstream da psicologia experimental estadunidense.

Antes de avançar nessa questão, salienta-se que, além da liberdade experimentada no Departamento de Fisiologia, outro fator crucial que incidiu na possibilidade de que sua tese de doutorado resultasse em ambicioso programa de pesquisa, com particularidades evidentes, foi a possibilidade de manter o seu, já descrito, desconhecimento e, por conseguinte, distanciamento da psicologia sem riscos de sanções contra sua postura. Em outros termos, sua transferência para o Departamento de Fisiologia o isentou ainda mais de qualquer necessidade de adesão àquilo que ele alegou sempre conhecer de modo incipiente, a saber, a produção científica da psicologia experimental. Porém, a despeito de ser plausível supor o desconhecimento de Skinner em relação à psicologia experimental no início de seu doutorado, a partir do final de seu primeiro semestre em Harvard a manutenção de relatos sobre o desconhecimento do saber psicológico não pode mais ser interpretada como resultado exclusivo de sua formação em outro campo do conhecimento e de seu pouco tempo de inserção na área. Daquele momento em diante, esse tipo de alegação se conservou e foi fortalecido quando havia indícios de que o grau de conhecimento de Skinner acerca da psicologia já não era mais tão incipiente como ele alegava. Ademais, os mesmos relatos passaram a ser acompanhados de discursos de negligência e desprezo pela psicologia. Na passagem a seguir, Skinner avalia seu conhecimento psicológico no período de seu doutorado:

Eu nunca tinha sequer lido um texto de psicologia como um todo. Até mesmo como um 'psicólogo interessado em psicologia animal' eu sabia pouco sobre os erros cometidos pelos ratos em labirintos, ou o número de escolhas feitas na aprendizagem de uma discriminação, ou os processos simbólicos ou insights de primatas - e eu nem tinha qualquer interesse em saber (Skinner, 1979, p. 179).

${ }_{7}$ É provável que a postura e as condições estabelecidas por Crozier reproduzissem parcialmente seu próprio processo de formação como aluno de pós-graduação, visto que seu mentor, Jacques Loeb, incentivava pesquisas individuais e mantinha um clima informal e descontraído de trabalho em seu laboratório (cf. Osterhout, 1928). 
Skinner assegurou que, ao ler o trabalho de outros psicólogos do início da década de 1930, veiculados em periódicos como o American Journal of Psychology, sempre pensava que tal literatura não fazia sentido e que deveria haver maneira melhor de tratar tudo aquilo. Por isso, afirmou: "eu nunca aprendi como ler a 'literatura' em psicologia, e a literatura permaneceu largamente ilegível para mim” (Skinner, 1979, p. 34).

As participações dele nas disciplinas de psicologia durante o doutorado também sugerem a manutenção do discurso de desconhecimento acompanhada de negligência em relação à produção científica da área. Algo notado, por exemplo, quando descreveu que, ao término de seu doutorado, foi exigido que realizasse exames para comprovar conhecimento mínimo sobre psicologia. Além de afirmar estar despreparado para aqueles exames, Skinner (1979, p. 34) recordou ter concluído somente dois cursos de psicologia durante todo o doutorado e nenhum deles abarcou de forma substancial a produção desse campo de conhecimento. Igualmente, assumiu que suas notas nas disciplinas foram aquém do esperado para um aluno razoável. Mas Skinner não lamentou a situação, pois se sentia aliviado por não precisar aprender mais psicologia em Harvard. "Daquele ponto pra frente, com apenas duas ou três exceções, eu me inscrevi para cursos de pesquisa [pesquisa em psicologia] que faziam pouco mais do que garantir ao administrador que eu estava pagando minhas taxas" (Skinner, 1979, p. 34).

Das descrições de desconhecimento e de desdém acerca da produção do campo da psicologia, nos sete primeiros anos de Skinner em Harvard e ao longo de sua carreira, não se pode, como mencionado, concluir sua real desinformação e absoluta negligência pela área. Isso porque, em mais de uma ocasião, à medida que avançava em seu doutorado e, posteriormente, durante seu pós-doutorado, Skinner emitiu vários comentários críticos, algumas vezes pormenorizados, sobre pesquisas e teorias de expoentes de distintos ramos da psicologia experimental. Portanto, não obstante fizesse questão de salientar seu escasso conhecimento e seu desprezo pelo saber psicológico, naquele momento e ao longo de sua carreira, há indícios de que eles eram menos expressivos do que sempre alegou (cf. Cruz, 2013). ${ }^{\mathbf{8}}$

Os relatos de desconhecimento acerca da produção científica da psicologia são interpretados menos como desonestidade intelectual de Skinner e mais como representação de sua precoce intenção de instaurar uma nova ciência do comportamento, que, por conseguinte, designa sua postura iconoclasta desde o ingresso em Harvard. Nesse sentido, avaliar positivamente o trabalho de outros psicólogos significava não

8 Algumas provas disso são seus trabalhos como resenhista de periódicos estrangeiros de psicologia durante o doutorado (cf. Skinner, 1979, p. 12) e suas análises de trabalhos de psicólogos como Clark L. Hull (cf. Skinner, 1979 , p. 148, 177, 179, 184, 197, 204-206, 214, 227, 231, 232, 269-271, 3०1, 3०5, 326), Edward C. Tolman (cf. Skinner, 1979, p. 83, 121, 203, 204, 206, 207, 209, 214, 221, 223, 224, 227, 231, 232, 312, 323), Wolfgang Kohler (cf. Skinner, 1979, p. 10, 11, 30, 31 , 52, 73, 154, 155) e Kurt Lewin (cf. Skinner, 1979, p. 224, 232, 246), entre outros. 
menos que a diminuição de suas próprias chances de sucesso no campo psicológico. Posição assumida pelo próprio Skinner (cf. 1979, p. 270) ao lamentar, no final da década de 1930 e início da década de 1940, a falta de reconhecimento de sua produção científica por parte de psicólogos como Tolman e Hull e assumir, ulteriormente, que isso não significou um isolamento autocentrado, mas que todos eles buscavam tornar suas explicações do comportamento hegemônicas (cf. Cruz, 2011).

\section{A tRANSGRESSÃo DO GONGEITO DE REFLEXo como ReSUltado parGial das vinculações institugionais de Skinner}

Como exposto, a historiografia do behaviorismo skinneriano menciona o desconhecimento de Skinner acerca da psicologia e o provável papel de fatores microssociais, entre eles a vinculação ao Departamento de Fisiologia e a Crozier e o decorrente afastamento da psicologia, como partes da explicação da emergência de sua ciência. No entanto, tais elementos figuram de forma genérica na explicação desse quadro histórico ou, no melhor dos casos, como hipóteses ainda a serem investigadas. O foco desses trabalhos foi a história do desenvolvimento conceitual e empírico do projeto científico de Skinner.

A ênfase no desenvolvimento conceitual e empírico do sistema científico de Skinner e a ausência de apreciação de fatores institucionais e de seus desdobramentos não desqualificam as análises conceituais do behaviorismo skinneriano, como aquelas desenvolvidas por Sério (1990) e Coleman (1987) e citadas na introdução deste artigo. Estudos como esses, por delinearem com riqueza de detalhes o desenvolvimento do projeto científico, fornecem, aos interessados na historiografia do behaviorismo, não menos que informações valiosas para uma complementação entre a história conceitual e a história social - nesse caso microssocial-desse campo de conhecimento.

Com efeito, a afiliação de Skinner ao Departamento de Fisiologia Geral comandado por Crozier possibilitou acesso imediato às condições que o fizeram escolher aquele ambiente para a realização de seu doutorado. A disponibilidade de espaço, tempo e financiamento para empreender individualmente suas pesquisas, sem a imposição de temas e métodos de investigação, foram as mais evidentes provas disso. Não por acaso, em menos de dois anos, de 1929 a 1930, Skinner concretizou entre sete e oito projetos de pesquisa, muitos dos quais efetuados de modo simultâneo (cf. Coleman, 1981; Sério, 1990; Skinner, 1979). Tais projetos tiveram como finalidade o aperfeiçoamento de instrumentos capazes de prover condições para que a emissão de respostas comportamentais de sujeitos experimentais infra-humanos ocorresse o mais rápido possível, sem a necessidade de intermediação direta ou de supervisão do experimentador e, sobretudo, que fossem registradas de forma automatizada. O objetivo central das pes- 
quisas era a procura e a exposição gráfica da regularidade comportamental de organismos intactos (cf. Coleman, 1981; Sério, 1990; Skinner, 1956, 1979).

A caracterização completa dessas pesquisas seria, como sugere Coleman (1987), uma tarefa quixotesca. Porém, a descrição das formulações teóricas e empíricas na tese de doutorado de Skinner, posteriormente identificadas como partes essenciais da origem do principal conceito de sua ciência (condicionamento operante) e de seu método de pesquisa (delineamento experimental de sujeito único), parece ser suficiente para os propósitos deste trabalho. Pois sugerem como o aparente desconhecimento e a negligência de Skinner em relação ao conhecimento psicológico e sua vinculação ao Departamento de Fisiologia Geral e a Crozier implicaram a probabilidade de determinadas especificidades da versão inicial de sua ciência do comportamento surgirem naquele contexto.

A primeira parte da tese de doutorado de Skinner foi publicada em 1931, no artigo "The concept of reflex in the description of behavior". Nela, a história da evolução do conceito de reflexo é delineada a partir de Descartes, Robert Whytt, Marshall Hall, Sherrington e outros responsáveis pelo desenvolvimento da noção. Para Skinner (1931), o conceito de reflexo expresso em tais autores estava fundamentado, de uma maneira ou de outra, na demonstração observacional da repetida correlação entre a apresentação de um estímulo e um movimento discreto do organismo, uma resposta. Historicamente, o significado operacional do reflexo naqueles autores, embora apresentasse progressos, mantinha a definição daquele fenômeno imprecisa devido a pressuposições teológicas e metafísicas responsáveis por defini-lo como involuntário, inconsciente e inato. Por essa razão, na sua visão, o conceito de reflexo, em maior ou menor medida, sempre foi analisado com base em fatos incapazes de fundamentá-lo cientificamente.

Portanto para Skinner (1931) havia uma limitação inerente ao conceito de reflexo, mas ele não desprezou o avanço desse conceito nas pesquisas de fisiologistas do final do século xix e início do século xx, como Sherrington, Magnus e Pavlov. Tal avanço foi todavia limitado porque os pesquisadores mencionados se dedicaram especialmente às investigações anatômicas explicadas quase sempre por mediações físico-químicas de episódios típicos existentes na correlação estímulo-resposta de um reflexo. Logo, investigações limitadas para interpretar aquilo que Skinner avaliou como positivo na noção de reflexo: a possibilidade de descrição de sua natureza relacional e sua aplicação à descrição do comportamento total de organismos intactos (cf. Sério, 1990; Skinner, 1931).

Como mencionado, a insuficiência do conceito fisiológico de reflexo não fez com que Skinner o descartasse, pelo contrário, viu nele a possibilidade de transposição para uma ciência do comportamento, pois a correlação estímulo-resposta, na sua perspectiva, independia de qualquer investigação fisiológica. A descoberta e a definição dessa correlação no comportamento de organismos intactos tornavam desnecessárias as pes- 
quisas anatômicas, o que implicava, entre outras questões, a inédita inclusão de uma ciência do comportamento no mesmo patamar da fisiologia. Mais do que isso, Skinner ambiciosamente supôs que os avanços de uma ciência do comportamento dos organismos intactos levariam a fisiologia a ser dependente daquela ciência descritiva do comportamento e não o contrário, como era presumido naquele momento (cf. Coleman, 1985b; Sério, 1990; Skinner, 1931). 9

Dessa breve descrição conclui-se que Skinner foi além da produção de uma nova versão historiográfica do conceito de reflexo. Desenvolveu uma variante desse conceito, o que efetuou ao transpor a noção de reflexo para o centro de sua proposta de uma ciência do comportamento preocupada com o comportamento dito voluntário de organismos intactos.

Outra singularidade conceitual do uso que Skinner fez do conceito de reflexo em sua proposta inicial de uma nova ciência do comportamento é notada na diferenciação estabelecida, na primeira parte de sua tese de doutorado, entre leis "primárias" ou "estáticas" do reflexo e leis "secundárias" ou "dinâmicas" do reflexo (Skinner, 1931, p. 451-4). Diferenciação que o afastou tanto da fisiologia praticada em Harvard quanto da psicologia experimental versada naquela instituição e, em parte expressiva, da psicologia experimental desenvolvida nos Estados Unidos.

As leis "primárias" ou "estáticas" representam quantitativamente a sujeição de atributos da resposta reflexa, como latência e duração, a determinadas propriedades do estímulo eliciador, por exemplo, a intensidade e a quantidade de estimulação, respectivamente. Tais leis indeléveis em uma visão fisiológica do reflexo foram percebidas por Skinner (1931) como prova da natureza reflexa do comportamento. Porém, para ele, as relações estáticas do reflexo seriam também subordinadas a outras variáveis que não o estímulo eliciador. Skinner as denominou de "terceiras variáveis", as quais são definidas pelo estado de um organismo quando submetido a alguma droga, pelo número de eliciações de respostas, entre outras condições.

As leis "secundárias" ou dinâmicas do reflexo, por sua vez, representam quantitativamente que a relação estática é necessariamente subordinada, em nível operacional, a uma terceira variável específica: o número de reforços responsáveis por determinar mudanças na força do reflexo medidas pela taxa de respostas de pressão à barra, no comportamento de organismos intactos. Com essa definição, Skinner violava o conceito de reflexo, uma vez que destituía o valor dado ao estímulo eliciador como principal variável de controle do comportamento, em favor do foco no processo resposta-estímulo reforçador e as mudanças na força do reflexo (cf. Sério, 199o; Cruz e

9 Segundo Coleman (1985b, p. 305), em publicações posteriores Skinner retornou para o mesmo ponto de vista maverick de que a psicologia comportamental é propedêutica para as ciências do sistema nervoso. 
Cillo, 2008). Assim, embora Skinner tenha especificado a história do conceito de reflexo como a evolução de técnicas capazes de descobrir um número cada vez maior de comportamentos por meio da identificação de estímulos eliciadores, sua extensão do conceito de reflexo foi determinada pela busca de leis dinâmicas abstraídas das mudanças na força do reflexo, medidas pela taxa de respostas. Em suma, seu foco de análise nesse caso foi a resposta e não o estímulo eliciador.

Não obstante seja evidente a transgressão do conceito de reflexo, Skinner se manteve supostamente inconsciente de que sua proposta era incompatível com uma definição reflexa do comportamento, visto que explicava o alto nível de variabilidade no comportamento de organismos intactos, presente nas leis dinâmicas, como parte daquele fenômeno comportamental. Em outras palavras, na perspectiva de Skinner, a variabilidade - uma anomalia indesejável e conflitante com uma explicação reflexa e mecânica do comportamento - era supostamente excluída por sua inclusão nas leis dinâmicas do comportamento (cf. Coleman, 1981, 1985a, 1985b; Sério, 1990; Skinner, 1931). Mesmo com essas transgressões, Skinner propôs seu programa de pesquisa como parte de um modelo reflexo de explicação do comportamento. Muito embora sua acepção de reflexo infringisse a definição aceita desse conceito: a ênfase na correlação necessária entre estímulo eliciador e resposta.

A violação da noção de reflexo se torna mais perceptível quando observado que, em correspondência com o uso do conceito, o método desenvolvido por Skinner, igualmente, infringiu algumas regras das pesquisas fisiológicas e psicológicas que investigavam o comportamento reflexo. Assim, apesar da ênfase quantitativa de Skinner, naquele momento voltada para a medição da taxa de respostas individuais, Coleman (1987) mostra que algumas de suas fontes de inspiração, como Watson, Pavlov, Sherrington e Magnus, não recorreram de modo predominante a uma perspectiva quantitativa em suas pesquisas. Por essa razão, a ênfase quantitativa localizada nas primeiras pesquisas de Skinner era originada da influência de Crozier e não dos autores que o proveram da definição inicial de reflexo. Porém, seu conhecimento acerca de métodos quantitativos era incipiente e, por mais que Crozier o tenha levado a procurar a ordem quantitativa no comportamento dito livre, não é clara a semelhança entre a abordagem de Crozier e a abordagem inicial de Skinner. Como sugere Coleman (1987), a afinidade entre os dois pesquisadores se deu, no melhor dos casos, no apreço que tinham por uma espécie de quantificação de menor significância matemática. Ainda assim, tal paridade era apenas parcial, pois Skinner

não tinha o background quantitativo para se tornar um discípulo de Crozier, o que, além disso, ele não tinha a menor vontade de ser (B. F. Skinner, comunicação pessoal, julho, 1985). No entanto, a estratégia científica de Skinner como um 
aluno-pesquisador da pós-graduação era assumir que a regularidade, pelo menos de um tipo quantitativo simples, existia no comportamento do organismo de movimentos livres, e procurou demonstrar isso em suas várias preparações (Coleman, 1987, p. 50).

Nas primeiras pesquisas no Departamento de Fisiologia, Skinner chegou a efetuar análises quantitativas com o uso de logaritmos. $\mathrm{O}$ motivo para tanto foi seu contato com procedimentos quantitativos modelares da literatura fisiológica, da qual se aproximou ao frequentar disciplinas do Departamento de Fisiologia e conhecer as investigações de Crozier e seus alunos (cf. Skinner, 1979; Coleman, 1987). Entretanto, a adoção de métodos quantitativos nas pesquisas de Skinner foi parcial e temporária, pois ele não estava preocupado com valores quantitativos específicos, mas com a possibilidade de confirmação da regularidade quantitativa do comportamento (cf. Skinner, 1956, 1979, 1984a; Coleman, 1987). Em outro trabalho, Coleman (1985b) apoia essa interpretação com base na identificação do declínio do recurso a procedimentos quantitativos nas pesquisas de Skinner durante a década de 1930 e o início da década de 1940. Além disso, ainda que, em pesquisas após o doutorado, Skinner tenha utilizado determinada função de potência com algum expoente, sua finalidade foi observar a regularidade do fenômeno comportamental e dela abstrair conclusões não quantitativas relevantes (cf. Coleman, 1987; Skinner, 1979).

Como já foi exposto, no nível operacional, a descrição da regularidade comportamental procurada por Skinner se deu por meio da análise do que ele designou, na parte experimental de sua tese, como as mudanças na força do reflexo medidas em uma pesquisa sobre a taxa de resposta de ingestão de alimentos. Ele lembrou, no entanto, que o problema de usar essa medida era que ela não compunha a lista de medidas de pesquisadores como Sherrington e Magnus. Mais do que isso, ao concentrar a análise experimental no comportamento de sujeitos tomados individualmente, abolindo a comparação entre eles, os primórdios do método de pesquisa de Skinner - o delineamento experimental de sujeito único - apresenta-se como incompatível com aquilo que começa a consagrar-se como indispensável na pesquisa em psicologia experimental estadunidense a partir do início da década de 1930: o uso de grupos de controle com elevado número de sujeitos experimentais, de teste de hipóteses e a análise dos dados por meio de estatística inferencial (cf. Rucci \& Tweney, 1980).

Em função do quadro geral da emergência do projeto científico skinneriano e suas especificidades conceituais e de método, argumenta-se que o relativo desconhecimento e o desprezo de Skinner em relação à psicologia e sua vinculação ao Departamento de Fisiologia e a Crozier exerceram papel fundamental em sua produção científica, uma vez que denotam provável relação com o avanço de sua proposta científica. 
Quanto mais Skinner manteve-se distante da psicologia e menos obrigado a seguir as regras da psicologia e da fisiologia, mesmo inserido em um Departamento de Fisiologia, bem como foi incentivado a se orientar por interesses individuais, mais o seu projeto de ciência do comportamento distanciou-se de regras canônicas da psicologia experimental e da própria fisiologia.

Os efeitos do desconhecimento de Skinner acerca da psicologia experimental de sua época e seu isolamento em Harvard foram assumidos por ele (cf. Skinner, 1970, p. 10) quando afirmou, mais de três décadas mais tarde, que sua tese de doutorado apresentava vaga conexão com a psicologia praticada naquela instituição e com a psicologia experimental estadunidense como um todo. Além disso, apontou que suas inovações científicas eram fruto, em parte, de sua negligência acerca da produção científica da psicologia experimental. Ao abordar a origem do sistema científico exposto em seu primeiro livro publicado em 1938 - que apresentou muitos resultados derivados de seu doutorado e de seu pós-doutorado em Harvard -, Skinner argumentou que "com o que o comportamento dos organismos pareceria hoje em dia se eu não tivesse negligenciado meus contemporâneos naquela época? Estaria cheio de labirintos temporais, 'balanço centrífugo', 'insight', plataformas de salto de Lashey, aprendizagem latente, e Deus sabe mais o quê" (Skinner, 1984a, p. 255-6).

Igualmente, vale salientar que Skinner promulgou a defesa do conceito de reflexo como base de uma ciência do comportamento inserida em um Departamento de Fisiologia. Com isso, era presumível o surgimento de questionamentos e obstáculos, visto que, além de transgredir a noção de reflexo - autêntico representante da tradição fisiológica -, Skinner (1931) conferiu primazia à ciência do comportamento em relação à ciência fisiológica. Posição facilitada pela inexistência de controle rígido de regras científicas e pela liberdade oferecida por Crozier, o qual, além de não saber ao certo o que Skinner pesquisava, incentivava a busca de interesses individuais, ainda que fossem incompatíveis com as pesquisas realizadas por ele. Desse modo, o jovem Skinner, que não havia sido submetido a nenhum processo de disciplinarização na psicologia, também não foi obrigado a seguir de forma estrita regras científicas da fisiologia. Não por acaso Skinner se afastou gradativamente do tipo de pesquisa realizada no Departamento de Fisiologia e, concomitantemente a esse afastamento, mostraramse cada vez mais frequentes seus relatos de sentimento de liberdade, autonomia, segurança e satisfação com os resultados de suas pesquisas.

Os fatores abordados até este ponto são consonantes com aquilo que Kuhn (2006) descreve como os elementos responsáveis por um jovem cientista produzir inovações significativas em um campo do conhecimento. $\mathrm{O}$ autor remete ao parco tempo de estudo em uma área, à liberdade científica, à decorrente falta de controle institucional e, por sua vez, ao pouco comprometimento com as regras de uma ciência como condições 
favoráveis para que cientistas neófitos sejam responsáveis por empreender inovações que incidem em revoluções científicas. Em outras palavras, essas condições são necessárias, em significativa proporção, para que jovens pesquisadores realizem formulações científicas com alto grau de criatividade, desencadeadoras de mudanças paradigmáticas em uma ciência.

Ameniza-se, contudo, a extensão dessa interpretação. Primeiro, porque Kuhn (2006) desconsidera a possibilidade da existência de paradigmas na psicologia e, em segundo lugar, pois mesmo que a transgressão do conceito de reflexo efetuada por Skinner - ao dar atenção à variabilidade do reflexo e ao processo resposta-estímulo ao invés do processo estímulo-resposta - seja semelhante a um momento de identificação de anomalias científicas desencadeadores de crises e sua decorrente resolução, a princípio, não é possível afirmar se ele trabalhou como se houvesse qualquer crise na tradição de pesquisa reflexológica (Sério, 1990). De todo modo, nosso intuito é ressaltar a compatibilidade entre as condições que fizeram parte da história da emergência do seu projeto científico e aquelas apontadas por Kuhn (2006) como características de processos envoltos no surgimento de produções científicas inovadoras. No caso de Skinner, a formulação de uma nova forma de explicação e estudo do comportamento, que se distanciava das tradições de pesquisa fisiológica e psicológica existentes na primeira metade do século xx, nos Estados Unidos.

\section{Considerações FINAIS}

Os parâmetros estruturais da presente narrativa derivam da identificação de fatores históricos existentes nos primórdios da trajetória de Skinner em Harvard. As análises dos impactos desses elementos propiciaram bases para defender o argumento de que as inovações científicas exibidas ao final do seu doutorado - prelúdio do futuro conceito de condicionamento operante e de seu método de pesquisa - foram produto parcial de um contexto institucional específico, no qual a ausência de imposição de regras científicas e o incentivo a projetos individuais compatibilizaram-se com a postura iconoclasta do jovem Skinner.

Sugerimos que o valor deste estudo está em detalhar o percurso de Skinner e o desenvolvimento do behaviorismo, coisa inexistente em análises puramente conceituais, o que, por certo, não significa desconsiderar a pesquisa conceitual. Na verdade, supomos que análises como a proposta neste artigo auxiliam no trabalho de expansão da compreensão do behaviorismo skinneriano, ao diminuir a distância entre a história da vida de Skinner e sua obra. Em outros termos, entre pesquisa biográfica e pesquisa conceitual da ciência. 
Igualmente argumentamos que o presente artigo pode ser útil para o debate acerca das relações sociais na ciência, uma vez que Skinner forneceu um relato autobiográfico capaz de subsidiar uma descrição das relações informais e cotidianas na ciência. Com isso, Skinner destoa da tendência hegemônica na produção biográfica da ciência (cf. Brush, 1974; Greene, 2007) e da psicologia (cf. Ball, 2012), que, até o final da década de 1970, enfatizava a história dos "grandes homens", ou seja, sujeitos dotados de habilidades especiais e uma moral científica superior, que tinham suas históricas descritas sem qualquer referência aos contextos sociais de surgimento de suas extraordinárias realizações científicas. Neste artigo, o que se observa é justamente o oposto. Skinner fornece informações sobre sua vida científica que revogam radicalmente a concepção - ainda fortemente disseminada no ensino de ciências - do gênio científico no vácuo social.

Nesse sentido, não é exagero dizer que a autobiografia de Skinner propicia elementos para a construção de uma narrativa histórica da ciência na qual a vida de um cientista é concebida como algo que transpõe o espaço do laboratório e das formulações empíricas e lógicas da ciência. As memórias de Skinner se mostraram instigantes porque, mesmo sendo escritas em período histórico relativamente distante e em outro contexto geográfico, descrevem fatores que permeiam o cotidiano da ciência. Por isso não é surpresa que, ao entrar em contato com as memórias de Skinner, as memórias de seus leitores sejam também reavivadas. As circunstâncias e relações institucionais muitas vezes conflituosas no dia-a-dia acadêmico; os diversos tipos de controle não enunciados nesses ambientes que acabam por afetar os rumos da prática científica e a trajetória de pesquisadores; a necessidade ou muitas vezes obrigação de associar-se a determinados grupos e pessoas e afastar-se e atacar automaticamente outros; o papel do reconhecimento ou da falta dele; o desconhecimento e negligência por outros saberes científicos; o isolamento e suas consequências; e, claro, a informalidade que permeia a vida científica são apenas alguns temas recorrentes na narrativa autobiográfica de Skinner, que talvez estejam presentes na memória-vida de qualquer pesquisador. Se esse for o caso, mais do que lançar luz sobre si mesmo e sua biografia, as memórias de Skinner oferecem uma descrição histórica na qual seus leitores se surpreendem com um vasto panorama do funcionamento social da ciência.

Robson Nascimento da Gruz Pontifícia Universidade Católica de Minas Gerais, Brasil. robsoncruz78@yahoo.com.br 


\title{
Non-acquaintance and freedom in the path of a new behavioral science
}

\begin{abstract}
Historical interpretations of the initial career of B. F. Skinner include theoretical and empirical innovations of his stub of a behavioral science. Despite this historiographical commitment, one aspect has been treated as secondary in the analysis of this phase of Skinner's career, namely, the impacts of institutional context of Harvard University. The purpose of this article is to explore this aspect through the analysis of the institutionalized practices of the departments of psychology and general physiology of that university, and its relations with the emergence of the scientific proposal of Skinner and its peculiarities. According to our interpretation, some singularities of this proposal are more broadly understood as institutional conditions that enabled Skinner to distance himself from the mainstream of American experimental psychology. Finally, we suggest that even though this study refers to an eminent scientist at a specific historical context, it offers the possibility to illustrate the role of social controls inherent to scientific practices in the course of scientific careers.
\end{abstract}

KEYWoRds • Skinner. Scientific autobiography. Behavior analysis. History of psychology. History of behaviorism.

\section{REFERÊNGIAS BIBLIOGRÁFICAS}

BaLL, L. C. Genius without the "Great Man": new possibilities for the historian of psychology. History of Psychology, 15, 1, p. 72-83, 2012.

BJork, D. W. B. F. Skinner: a life. New York: Sheridan Books, 2006.

Brush, S. G. Should the history of science be rated x? Science, 183, 4130, p. 1164- ${ }^{-72}, 1974$.

CAPshew, J. H. Psychologists on the march: science, practice, and professional identity in America, 1929-1969. Cambridge: Cambridge University, 1999.

Cerullo, J. J. Skinner at Harvard: intellectual or mandarin? In: Smith, L. D. \& Woodward, W. R. (Ed.). B. F. Skinner and behaviorism in American culture. Cranbury: Associated University Presses, 1996. p. 21536.

Chiesa, M. Radical behaviorism: the philosophy and the science. Boston: Authors Cooperative, 1994.

Coleman, S. R. Historical context and systematic function of the concept of the operant. Behaviorism, 9, p. $207^{-25}, 1981$.

B. F. Skinner, 1926-1928: from literature to psychology. The Behavior Analyst, 8, 1, p. 77-92, $1985^{2}$. When historians disagree: B. F. Skinner and E. G. Boring, 193o. The Psychological Record, 55, p. 30114,1985 b.

. Quantitative order: B. F. Skinner's early research program, 1928-1931. The Behavior Analyst, 10, p. $47-65,1987$.

CRuz, R. N. Percalços na história da ciência: B. F. Skinner e a aceitação inicial da análise experimental do comportamento entre as décadas de 1930 e 194.0. Psicologia: Teoria e Pesquisa, 27, 4, p. 545-54, 2011. . B. F. Skinner e a vida científica: uma história da organização social da análise do comportamento. Belo Horizonte, 2013. Tese (Doutorado em Psicologia). Departamento de Psicologia, Universidade Federal de Minas Gerais.

Cruz, R. N. \& Girlo, E. N. P. Do mecanicismo ao selecionismo: uma breve contextualização da transição do behaviorismo radical. Psicologia: Teoria e Pesquisa, 24, 3, p. 375-85, 2008. 
Demorest, A. P. \& Sieged, P. Personal influences on professional work: an empirical case study of B. F. Skinner. Journal of Personality, 64, p. 24,3-61, 1996.

Dews, P. B. (Ed.). Festschrift for B. F. Skinner. New York: Appleton-Century Crofts, 1970.

Eldiot, C. A.\& Rossiter, M. W. (Ed.). Science at Harvard University: historical perspectives. Bethlehem: Lehigh University Press, 1992.

Elms, A. C. Skinner's dark year and Walden Two. American Psychologist, 36, p. 470-9, 1981.

Evans, R. I. B. F. Skinner: the man and his ideas. New York: Dutton, 1968.

Greene, M. T. Writing scientific biography. Journal of the History of Biology, 4. O, 4, p. 727-59, 2007.

Hoagland, H. \& Mitcheld, R. T. William John Crozier, 1983-1955. American Journal of Psychology, 69, 1, p. $135^{-8,1956 .}$

Iversen, I. H. Skinner's early research: from reflexology to operant conditioning. American Psychologist, 47,11, p. 1318-28, 1992.

KeLler, F. S. At my own pace: The autobiography of Fred S. Keller. New York: Sloan Publishing, 2009.

Krasner, L. Review of the shaping of a behaviorist by B. F. Skinner. Journal Applied Behavior Analysis, 13,

3, p. 519-21, 1980.

Kunn, T. S. A estrutura das revoluções científicas. São Paulo: Perspectiva, 2006.

Micheletto, N. Uma questão de consequências: A elaboração da proposta metodológica de B. F. Skinner. São

Paulo, 1995. Tese (Doutorado em Psicologia Social). Departamento de Psicologia, Pontifícia Universidade Católica de São Paulo.

Bases filosóficas da noção de relação funcional. Revista Brasileira de Terapia Comportamental e Cognitiva, 2, 2, p. 115-21, 2000.

Moore, J. Some historical and conceptual background to the development of B.F. Skinner's "Radical

Behaviorism", Part 1. The Journal of Mind and Behavior, 26, 1-2, p. 65-94, 2005a.

Some historical and conceptual background to the development of B.F. Skinner's "Radical

Behaviorism”, Part 2. The Journal of Mind and Behavior, 26, 1-2, p. 95-124, 2005b.

. Some historical and conceptual background to the development of B. F. Skinner's "Radical

Behaviorism", Part 3. The Journal of Mind and Behavior, 26, 3, p. 137-60, 2005c.

Moxley, R. A. From mechanistic to functional behaviorism. American Psychologist, 47, 11, p. 1300-11, 1992.

O'Donnell, J. M. The crisis of experimentalism in the 1920s: E. G. Boring and his uses of history. American Psychologist, 34, p. 289-95, 1979.

. The origins of behaviorism: American psychology, 1870-1920. New York: New York University Press, 1985 .

Osterhout, W. J. V. Jacques Loeb. The Journal of General Physiology, 8, p. 9-59, 1928.

Porter, T. M. Is the life of the scientist a scientific unit? Isis, 97, p. 314-21, 2006.

Quine, W. V. O. The time of my life: an autobiography. Cambridge: Bradford Books, 1985.

Rucci, A. J. \& Tweney, R. D. Analysis of variance and the "second discipline" of scientific psychology. Psychological Bulletin, 87, p. 166-84, 1980.

SAmELson, F. Struggle for scientific authority: the reception of Watson's behaviorism, 1913-1920. Journal of the History of the Behavioral Sciences, 17, 3, p. 399-425, 1981.

. Organizing for the kingdom of behavior: academic battles and organizational policies in the twenties. Journal of the History of the Behavioral Sciences, 21, 1, p. 33-47, 1985.

Sério, M. T. A. P. Um caso na história do método científico: do reflexo ao operante. São Paulo, 1990. Tese

(Doutorado em Psicologia). Departamento de Psicologia, Pontifícia Universidade Católica de São Paulo.

Shapin, S. The scientific life: a moral history of a late modern vocation. Chicago: The University of Chicago Press, 2008. 
Siegel, P. The meaning of behaviorism for B. F. Skinner. Psychoanalytic Psychology, 13, p. 343-65, 1996. Skinner, B. F. The concept of the reflex in the description of behavior. Journal of General Psychology, 5 , p. $422-58,1931$.

. A case history in scientific method. The American Psychologist, 11, 5, p. 221-33, 1956.

. Skinner... An autobiography. In: Dews, P. B. (Ed.). Festschrift for B. F. Skinner. New York: Appleton-

Century Crofts, 1970. p. 1-21.

. The shaping of behaviorist: part two of an autobiography. New York: Knopf, 1979.

Particulars of my life: Part one of an autobiography. New York: New York University Press, 1984a.

A matter of consequences. New York: New York University Press, 1984b.

Sмith, L. D. \& Woodward, W. R. (Ed.). B. F. Skinner and behaviorism in American culture. Cranbury: Associated University Presses, 1996.

Triplet, R. G. Harvard psychology, the psychological clinic, and Henry A. Murray: a case study in the establishment of disciplinary boundaries. In: EцLiot, C. A. \& Rossiter, M. W. (Ed.). Science at Harvard University: historical perspectives. Bethlehem: Lehigh University Press, 1992. p. 223-50.

Wiener, D. N. B. F. Skinner: benign anarchist. Needham Heights: Allyn/Bacon, 1996.

Weiget, J. A. B. F. Skinner. Miami: Twayne Publishers, 1977.

Woodward, W. R. Skinner and behaviorism as cultural icons: from local knowledge to reader reception. In: Sмith, L. D. \& Woodward, W. R. (Ed.). Skinner and behaviorism in American culture. Cranbury: Associated University Presses, 1996. p. 7-34. 